\title{
The Effect of Vibratory Milling on the Powder Properties of Zinc Oxide Varistors
}

\author{
Maura Kelleher \\ Technological University Dublin, maura.kelleher@tudublin.ie \\ M.S.J. Hashmi \\ Dublin City University, saleem.hashmi@dcu.ie
}

Follow this and additional works at: https://arrow.tudublin.ie/engmecdesignart

Part of the Ceramic Materials Commons, Mechanical Engineering Commons, and the Semiconductor and Optical Materials Commons

\section{Recommended Citation}

Kelleher, M.C. \& Hashmi, M.S.J. (2008). The effect of vibratory milling on the powder properties of zinc oxide varistors. Journal of Materials Processing Technology, vol. 201, no. 1-3, pp. 645-650. doi:10.1016/ j.jmatprotec.2007.11.163

This Article is brought to you for free and open access by the School of Mechanical and Design Engineering (old) at ARROW@TU Dublin. It has been accepted for inclusion in Articles by an authorized administrator of ARROW@TU Dublin. For more information, please contact arrow.admin@tudublin.ie, aisling.coyne@tudublin.ie, gerard.connolly@tudublin.ie.

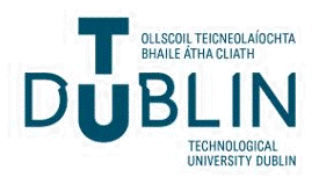




\title{
THE EFFECT OF VIBRATORY MILLING ON THE POWDER PROPERTIES OF ZINC OXIDE VARISTORS
}

\author{
M.C. Kelleher ${ }^{1}$ and M.S.J. Hashmi ${ }^{2}$
}

1. Department of Manufacturing and Design Engineering, Dublin Institute of Technology, Bolton St., Dublin 1, Ireland; email: Maura.Kelleher@dit.ie

2. School of Mechanical Engineering, Dublin City University, Glasnevin, Dublin 9, Ireland; email: $\underline{\text { Saleem.Hashmi@dcu.ie }}$

\begin{abstract}
The formation of powders from multi-elemental oxides for the subsequent formation of a green and sintered compact body is a major processing operation in the manufacture of $\mathrm{ZnO}$ varistors. The physical and chemical properties of the metal oxides are crucial not only for the formation of a varistor component with optimum microstructure and thus electrical characteristics but also for avoiding the introduction of flaws and reduced yield during subsequent manufacturing stages. The effect of vibratory milling using cylindrical zirconia media on the physical and chemical properties of the mixed multi-elemental oxide additives of a commercial $\mathrm{ZnO}$ varistor formulation was studied. These properties include particle size distribution, specific surface area, pore size distribution and zirconium concentration. They were evaluated by laser diffraction, Braunauer, Emmett and Teller (B.E.T.), mercury porosimetry and inductively coupled plasma (I.C.P.) analysis respectively. It was found that all of the physical and chemical properties of the metal oxide additives changed with increased duration of vibratory milling. The change in these properties was compared, a model of the powder morphology constructed and their significance analysed.
\end{abstract}

KEYWORDS: ZnO varistor; Vibratory milling; Powder properties; Zirconium concentration

\section{Introduction}

Zinc oxide varistors are semiconductor ceramic devices, which are widely used for voltage stabilization and transient surge suppression in electric power systems and electronic circuits. These ceramic devices exhibit high non-linear current-voltage characteristics, and each region of the I-V curve plays an important part in voltage stabilization and transient surge suppression [1-4].

The electrical performance of $\mathrm{ZnO}$ varistors critically depends on the nano-, micro-, and macrostructural characteristics. The microstructure of zinc oxide varistors is complex. It is polycrystalline and multiphase, with each phase having different dopants, dopant concentrations, shapes and sizes. It consists predominantly of zinc oxide grains, secondary phases including spinel and pyroclore, surrounded by a three dimensional network of bismuth rich phases [1,5]. Varistors with inhomogeneous microstructure can cause a large spread in current-voltage characteristics due to high local currents and this leads to the degradation of the varistor during electrical operation [2,68]. It is well documented that the electrical characteristics can be altered by varying the microstructure at the grain boundaries $[2,9,10]$. Careful control of the microstructure is required to produce a high performance varistor. An ideal varistor should consist only of homogenously 
distributed $\mathrm{ZnO}$ grains with highly resistive grain boundaries and without secondary phases [11]. Due to the many variables involved in the manufacturing process obtaining this ideal is difficult.

The method of preparation, crystalline size, additive homogeneity and chemical composition are the critical parameters to produce a better varistor material $[8,9]$. The relationship between powder properties and varistor electrical properties has been given considerable attention. All agree that to achieve a uniform sintered microstructure with a high level of grain growth control, a uniform green microstructure consisting of uniformly packed particles with a narrow distribution in size is required. The work can be categorized into four principle approaches taken; chemically derived mixed metal oxide routes [12,13], incorporation of $\mathrm{ZnO}$ seeds [14-17], prior preparation of secondary phases [18] and mechanically derived mixed metal oxide routes [19]. Addition of $\mathrm{ZnO}$ seeds was predominantly carried out to improve the manufacturability and the non-linearity of low voltage rated devices. Chemically derived powder routes have been given a lot of attention because they offer the advantages of atomic scale homogeneity, high specific surface areas and impurity control. However, apart from that reported by Puyane et al. [12], they have not been implemented widely on an industrial scale. This may be due to difficult processing and low yields. Another possibility may be the absence of mechanical milling.

Mechanical methods to prepare ceramic powders have mainly been studied on technical ceramics [20-22]. It was shown that in general the properties of the ceramics improved with decreasing powder particle size. Jeong et al. [21] illustrated the importance of media wear in addition to particle size on nano-composites. Maximum fracture strengths are obtainable provided media wear is below a threshold value. $\mathrm{M}^{\mathrm{c}}$ Ardle et al. [19] studied the effect of different mills; ball, shear, and attrition, on varistor metal oxide particle size and the electrical properties of radial devices. In general, the varistor voltage increased and the clamp ratio decreased with decreasing particle size obtained from the different mills. Even though attrition milling achieved the smallest particle size, the clamp ratio of the devices obtained did not follow the general trend. Media wear was not evaluated and may explain the deviation from the general trend.

The present study was conducted on a pilot scale with a vibratory mill to examine its effect using cylindrical zirconia media on the powder characteristics of mixed metal oxide additives (M.M.A.O.) so that optimum conditions of milling can be determined. A standard commercial metal oxide additive formulation typical of high voltage arresters was used. Particle size distribution, specific surface area, pore size distribution of the mixed metal oxides were evaluated and compared. I.C.P. analysis capable of determining parts per million (p.p.m.) concentrations was used to evaluate media wear.

\section{Experimental procedure}

\subsection{Reagents}

The metal oxide additives of a typical commercial $\mathrm{ZnO}$ high voltage arrester varistor composition was used; $\mathrm{Bi}_{2} \mathrm{O}_{3} 0.5$ mol. $\%, \mathrm{Sb}_{2} \mathrm{O}_{3} 1.0$ mol.\%, $\mathrm{MnO}_{2} 0.5$ mol.\%, $\mathrm{Co}_{3} \mathrm{O}_{4} 1.0$ mol.\%, $\mathrm{NiO} 0.5 \mathrm{~mol} . \%$ and $\mathrm{SnO}_{2} 0.5 \mathrm{~mol} . \%$. $\mathrm{ZnO}$, the main constituent of the varistor has a concentration of 96.0 mol.\%. The six metal oxides are collectively referred to as mixed metal oxide additives and abbreviated as M.M.O.A. These metal oxides were mixed and milled together using a vibratory mill.

\subsection{Equipment}

The vibratory mill (Sweeco Ind., model M-18) is a vertical mill with a capacity of 15 litres, lined with high-density poly-eurethane and filled with zirconia $3 / 4$ inch media, which are cylindrical with bevelled edges. An air pump circulated the slurry from the bottom to the top of the mill, where 
most of the slurry being milled is kept. Each vibratory mill trial used $5 \mathrm{~kg}$ of additives with 5 litres of deionised water.

\subsection{Milling}

Zero milling time represents no vibratory milling of the additives. The additives were mixed together in deionised water and stirred with a shear mixer for 30 minutes. Vibratory milling of the mixed metal oxide additives was carried out for 18 hours. Samples of the flowing slurry were taken at intervals of 1, 3, 6, 12 and 18 hours, and examined for particle size, specific surface area, and zirconium concentration. Intervals of 2, 6, and 12 hours were used for pore size analysis.

\subsection{Analytical Instrumentation}

The determination of particle size and distribution was carried out using a Malvern MasterSizer Laser Diffractometer. Samples were selected from free-flowing slurry rather than from a storage vessel where the powder particles within the slurry segregate. The distribution in particle size is represented at the 10, 50 and 90 cumulative percent particle size, denoted as D10, D50 and D90 respectively.

The Braunauer, Emmett and Teller (B.E.T.) surface area analysis was carried out using a Micromeritics Gemini III 2375 surface area meter. This instrumental technique is based on the B.E.T. isotherm method and uses helium as the carrier gas and nitrogen as the adsorbate gas. Samples were dried and degassed for 2 hours at $150^{\circ} \mathrm{C}$ to remove any surface organic or moisture contaminants. The specific surface area was calculated as per unit mass of powder.

The pore size distribution was determined using an Autoscan 33 Quantochrome mercury porosimetry, with a pressure range from 0 to 33,000 P.S.I.G. Samples were prepared using a similar method to that for specific surface area analysis.

Inductively coupled argon plasma analysis (I.C.P.) was used in this study to determine the concentration of zirconium. The instrument used was a Thermo Jarrell Ash AtomScan 25 spectometer. Solutions containing the sample to be assessed were prepared by digesting the powder in concentrated acid such as $\mathrm{HCl}$ under reflux for periods typically between 2 and 7 hours. Since it is a comparative technique, the relationship between emission intensity and concentration was determined using blank solutions and standard materials whose concentrations were known.

\section{Results}

The influence of vibratory milling on the powder properties of the M.M.O.A. and zirconium concentration (media wear) was investigated. The average and distribution in particle size, specific surface area, volume and distribution of pore size and zirconium concentration were all affected by the duration of vibratory milling. The changes in the powder characteristics can be divided into three stages, each corresponding to a different effect on the powder morphology. Stages one, two and three are between zero and the first hour, between the first and tenth hour, and between the tenth and eighteenth hour of milling, respectively.

\subsection{Particle size}

Laser diffraction of the milled M.M.O.A. showed a significant reduction in both the average and distribution in particle size (Figs. 1 and 2). Sub-micron particles were obtained after 10 hours. It appears that 10 hours is the optimum milling condition. Three stages can be seen in the reduction in particle size. 
The first stage occurs within the first hour of milling and involves a rapid reduction in average particle size from $5.5 \mu \mathrm{m}$ to $0.87 \mu \mathrm{m}$ and distribution in particle size (D10-D90) from $1.35-13 \mu \mathrm{m}$ to $0.87-3.59 \mu \mathrm{m}$. The rapid and large reduction in particle size together with the relatively low increase in specific surface area (Fig. 3), substantial reduction in both the pore volume (Fig. 4) and pores between 1 and 10 microns (Fig. 5) may be attributed to the fracture of large agglomerates. These large agglomerates consist of aggregates held together by relatively weak bonds and small surfaces, and are separated by large pores, the morphology of which is represented in stage 1 of Fig. 6.

In the next stage, between 1 and 10 hours, a slower but steady reduction in average to $0.45 \mu \mathrm{m}$ and distribution range to $0.13-1.0 \mu \mathrm{m}$, in particle size occurs. The majority of the particles are submicron. The corresponding steady increase in specific surface area and creation of pores between 0.01 to $1 \mu \mathrm{m}$ and 0.001 and $0.01 \mu \mathrm{m}$, suggests that the reduction in particle size at this stage may be attributed to the removal of primary particles from the aggregates as represented in stage 2 of Fig. 6. New surfaces are being created with the development of pores between the primary particles and their subsequent separation from the aggregates. Relatively strong bonds, possibly caused by slight fusion during the manufacturing process of the powder hold the primary particles together.

In the final stage (10 to 18 hours) very little change in the average and distribution range in particle size occurs. They reduce to $0.35 \mu \mathrm{m}$ and $0.11-0.96 \mu \mathrm{m}$ respectively. The corresponding slow but continued increase in specific surface area and reduction in size of pores between 0.001 and $0.01 \mu \mathrm{m}$ may suggest that this stage may be attributed to the creation of surface cracks on very small aggregates containing a few primary particles or soft slightly amorphous primary particles as shown in stage 3 of Fig. 6.

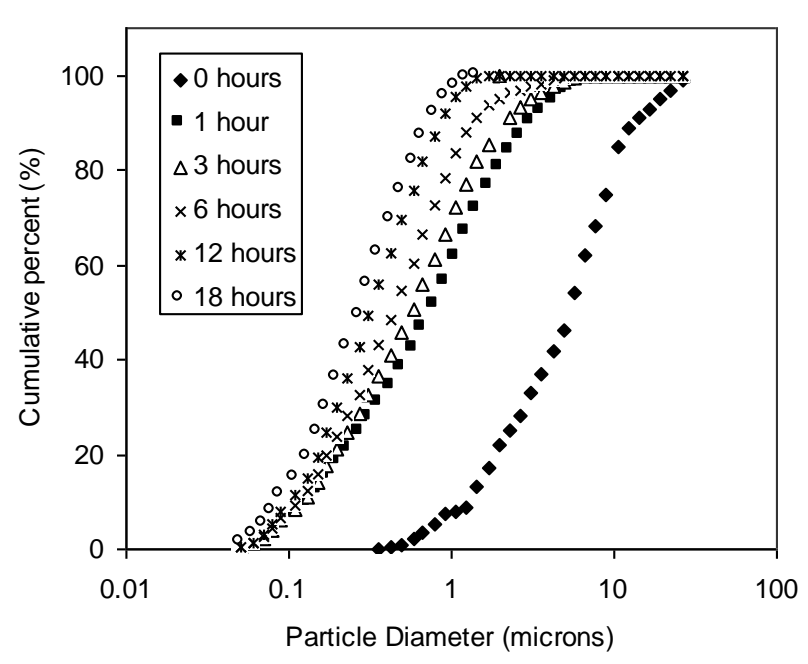

Fig. 1. Effect of vibratory milling time on particle diameter of mixed metal oxide additives.

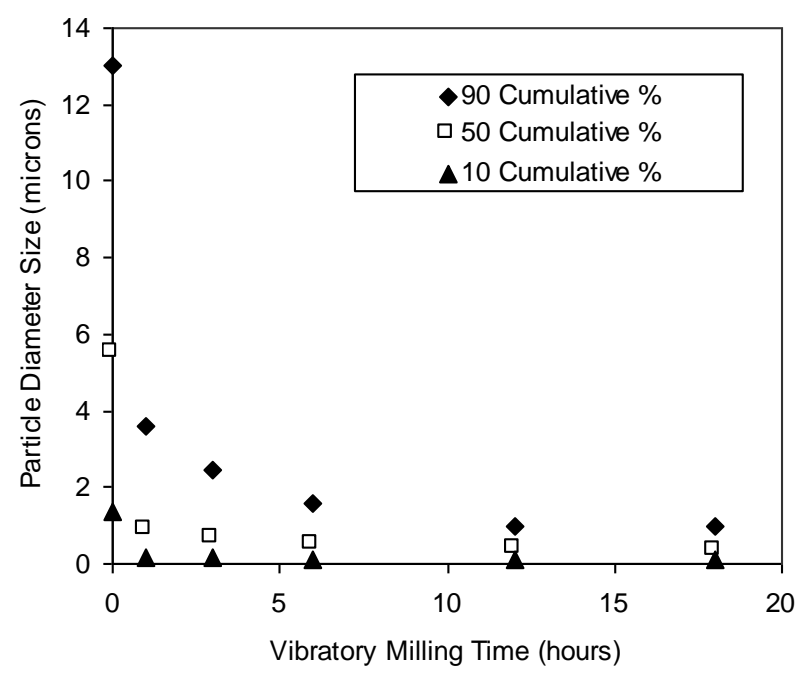

Fig. 2. Effect of vibratory milling time on particle size distribution (D10, D50 \& D90) of M.M.O.A.

\subsection{Specific surface area}

B.E.T. analysis (Fig. 3) showed an increase in specific surface area of the M.M.O.A. with increasing duration of vibratory milling. The specific surface area increased quickly during the first 10 hours of milling from 1.7 to $8.3 \mathrm{~m}^{2} / \mathrm{g}$ followed by a slower increase to $9.4 \mathrm{~m}^{2} / \mathrm{g}$ at 18 hours. The specific surface area increased by greater than five fold. This is a large increase even though some reagglomeration may have taken place during the removal of water from the slurry, as required for 
B.E.T. analysis. Increased densification of the powders during sintering may be expected due to the increase in specific surface area [23].

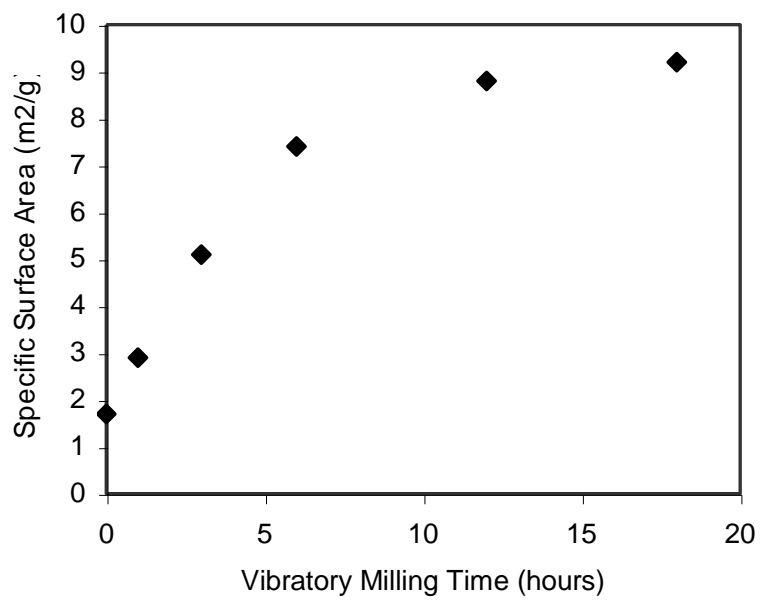

Fig. 3. Effect of vibratory milling time on specific surface area of mixed metal oxide additives.

\subsection{Pore volume, size and distribution}

The total volume of mercury intruded into the mixed metal oxide additives (Fig. 4) decreases substantially within the first two hours and remains almost constant for the remaining milling time up to 18 hours. This may suggest that 2 hours is the optimum duration of milling. However, after 2 hours the particles continue to decrease in size and the specific surface area continues to increase in magnitude. Fig. 5 indicates that this substantial reduction in pore volume may be attributed to the reduction in the large pores between 1 and $10 \mu \mathrm{m}$ present between aggregates within the agglomerates. Their removal may be caused by the deformation of the inter-aggregate bonds, weak enough to allow large and rapid reduction in particle size, but strong enough to resist the pressure exerted by mercury during porosimetry analysis. Better packing of the particles may be anticipated in the following processing stages with the removal of these large pores, leading to higher spray dried powder densities, higher green densities and thus reduced shrinkage and variation in shrinkages during sintering.

Along with the continued reduction in pores between 1 to $10 \mu \mathrm{m}$, the second stage of vibratory milling is characterised by the creation of a number of pore size distributions smaller than $1 \mu \mathrm{m}$. Two distinctive distributions can be seen (Fig.5) between 0.1 and $1 \mu \mathrm{m}$, and 0.01 and $0.1 \mu \mathrm{m}$. They may be attributed to those created between the primary particles within the aggregates and on the surfaces of the aggregates, respectively. Their size reduction with milling may be due to their continued creation and elimination, as the primary particles continue to separate from the aggregates. After 12 hours they are not completely eliminated suggesting that not all of the primary particles have been separated from each other. A higher energy milling technique may be required for their complete elimination. Complete separation of the primary particles would tighten the particle size distribution further.

\subsection{Zirconium concentration}

I.C.P analysis (Fig. 7) shows that zirconium was present in the M.M.O.A. after milling. The concentration of zirconium uptake from the media into the M.M.O.A. increased steadily at an 
average rate of 120 p.p.m./hour up to 10 hours. The steady increase in zirconium appears to correlate with the decrease in particle size, decrease in pore size and increase in specific surface area. However, between 10 and 18 hours of milling, even though laser diffraction analysis showed a very slow decrease in the particle size distribution, the zirconium concentration continued to increase at a slower average rate of 40 p.p.m./hour. The media continued to wear irrespective of the work carried out by the mill.

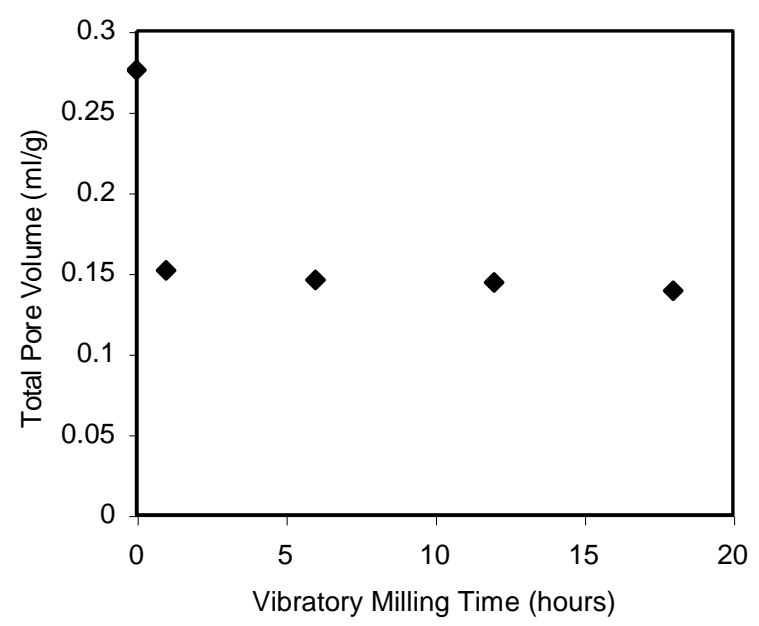

Fig. 4. Effect of vibratory milling time on total pore volume of mixed metal oxide additives

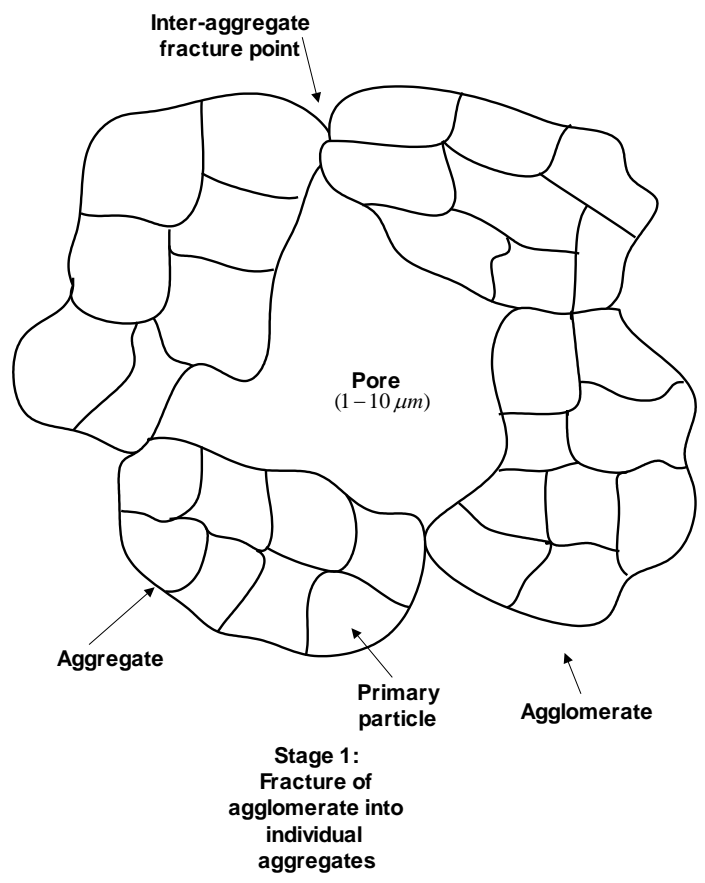

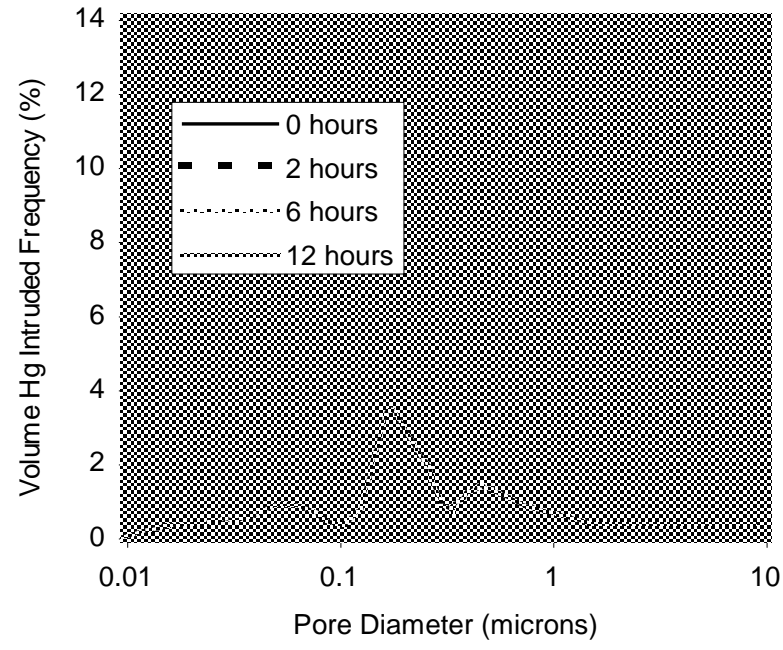

Fig. 5. Effect of vibratory milling time on pore diameter frequency of mixed metal oxide additives

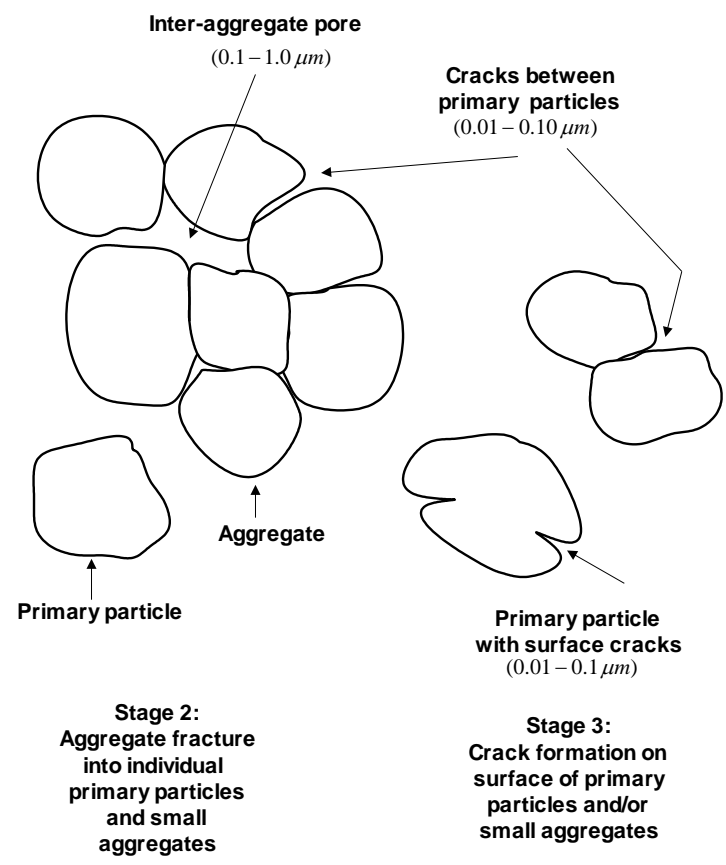

Fig. 6. Change in M.M.O.A. powder morphology with vibratory milling. 


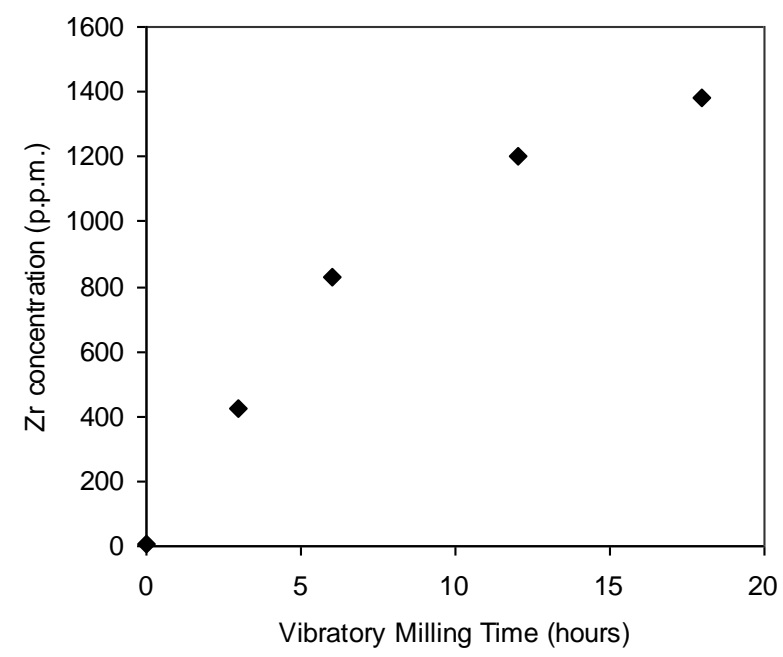

Fig. 7. Effect of vibratory milling time on zirconium concentration of mixed metal oxide additives

\section{Discussion}

Wear of the Zirconia media appears to be accelerated by the amount of work done by the mill in reducing the particle size. The concentration of zirconium as determined by I.C.P. analysis corresponds with the separation of the aggregates within the agglomerates (stage 1) and the separation of primary particles from the aggregates (stage 2) during vibratory milling. The rate of uptake of zirconium from the media was at its minimum when most of the primary particles have been separated (stage 3). If the presence of zirconia in M.M.O.A. has a negative effect on the performance of the final varistor and its concentration needs to be kept at a minimum, then the as-received metal oxides should be in their un-agglomerated, un-aggregated individual primary particle form. The purpose of the milling stage in the manufacturing process would then be to mix the constituent metal oxides rather than reduce them in size also.

Within the M.M.O.A. are 6 different metal oxides each with their own powder characteristics and milling behaviour. In this investigation they have been treated as one. However, some metal oxides may have reduced in size easily, while others may have been more resistant. The later may have prevented the average and distribution in particle size from being reduced any further than that observed. These metal oxides when received may have had large primary particles and/or a wide size distribution of primary particles and/or strong inter-primary particle bonds within the aggregates. If the primary particles are smaller, the spread in distribution tighter, and the inter-primary particle bonds are weaker, within the M.M.O.A., then the overall capability of obtaining particles closer to $0.05 \mu \mathrm{m}(50 \mathrm{~nm})$ by vibratory milling would be greater. The minimum particle size observed at zero cumulative percent (Fig. 1) is $0.05 \mu \mathrm{m}$.

The particle size and spread in size achieved after vibratory milling for periods equal and greater than 10 hours is significantly smaller than those observed at zero milling. Thus when mixed with the main varistor constituent, $\mathrm{ZnO}$, the homogeneity of the M.M.O.A. surrounding each $\mathrm{ZnO}$ particle would be expected to be higher than those obtained at zero milling. It is thought that higher homogeneity of the additives around the $\mathrm{ZnO}$ crystals would be expected to result in better grain growth control during sintering and thus electrical performance [12-16]. Apart from more efficient milling and obtaining particles closer to $50 \mathrm{~nm}$, a reduction in the primary particle and inter-primary particle bond strength within the aggregates of the received 
metal oxide additives would allow an even higher uniformity of additives around the $\mathrm{ZnO}$ crystals than that obtained with the current additives by vibratory milling.

Chemically derived methods offer a number of advantages including atomic scale mixing and impurity control. However, varistors tend to be produced in a range of different voltage ratings and energy capabilities. More than one varistor formulation is required. Mixed metal oxide additives derived from a chemically derived method would be designed for one varistor type rather than a range of varistors, thus decreasing versatility and increasing inventory. A number of processing stages are required to manufacture chemically derived M.M.O.A. [12,13], increasing the duration of ordering to delivery of product. If the primary particles of all of the received individual metal oxides are reduced to less than $0.1 \mu \mathrm{m}$ and a distribution in size to approximately $0.05-0.1 \mu \mathrm{m}$, vibratory milling of the oxides would not be equivalent to atomic scale mixing, but would offer the possibility of increased homogeneity compared to that expected from the metal oxides used in this study, while maintaining current versatility, inventory and duration between ordering and product delivery.

Most of the work done by vibratory milling in reducing the particle size appears to have been achieved at 10 hours (Fig. 2). The particle size and distribution are at their minimum. Supporting B.E.T. surface area and mercury porosimetry analysis suggests that this limitation is in part due to the morphology of the received metal oxide powders. Another limitation may be media size. Increasing slurry to media contact with the use of smaller media may contribute to more efficient milling. However, a reduction in media size may increase media wear rate [24].

I.C.P. analysis showed the presence of zirconium in the M.M.O.A. after milling even though in the p.p.m. range. Its concentration increased with increased time of milling and corresponds with the reduction in particle size of the M.M.O.A. McArdle et al. [19] investigated four different mills. Analysis of the varistor voltage and clamping voltage data reported shows an increase in varistor voltage and decrease in clamp ratio of the radial devices with decreasing particle size of the M.M.O.A. Even though attrition milling showed a lower and tighter particle size distribution compared to ball, vibratory and turbula milling, the electrical characteristics of the varistors formed did not follow the general particle size - electrical performance trend. This non-conformance may have been due to zirconia concentration. Media wear was not analysed and the media material used not mentioned. Attrition milling may have been carried out using a different grade of zirconia to that used in the other mill types and/or for shorter durations, causing different concentrations of zirconia in the M.M.O.A. The presence of $\mathrm{ZrO}_{2}$ may have an independent affect on the electrical performance of $\mathrm{ZnO}$ varistors.

Knowledge of the effect of zirconia concentration on the electrical performance of commercial $\mathrm{ZnO}$ varistor formulations is scarce. The presence of $\mathrm{ZrO}_{2}$ in $\mathrm{ZnO}$ varistors is considered by Tsutomu [25] and Masaaki [26] as a contaminant, impairing voltage stability, and should be 'nipped in the bud'. Fan et al. [27] investigated the effect of 10 vol. $\%$ of $\mathrm{ZrO}_{2}$ in $\mathrm{ZnO}$ and found it to reduce the density and grain size of $\mathrm{ZnO}$. Its presence inhibited the grain growth of $\mathrm{ZnO}$. Kim et al. [28] used zirconia instead of antimony and found its presence in high concentrations up to $10 \mathrm{vol}$. $\%$ as having a positive effect on many of the electrical characteristics of $\mathrm{ZnO}$ varistors containing three metal oxide additives (bismuth, cobalt and manganese). Antimony, nickel and tin oxides were not included. Increasing concentrations of $\mathrm{ZrO}_{2}$ were found to cause a decrease in grain size, an increase in varistor voltage, an increase in non-linear coefficient $(\alpha)$, and a decrease in clamping ratio. The leakage current varied with concentration. A commercial $\mathrm{ZnO}$ varistor with similar voltage rating was not used to compare the electrical data. 


\section{Conclusions}

The influence of vibratory milling on the powder properties of the mixed metal oxide additives of a typical commercial high voltage $\mathrm{ZnO}$ arrestor formulation was investigated along with media wear. All of the powder characteristics were affected by vibratory milling.

Sub-micron particles were achieved after 10 hours of milling. Analysis of the physical characteristics indicates that 10 hours is the optimum duration of milling. Three general stages were observed, which are attributed to agglomerate reduction, separation of primary particles from aggregates and crack initiation on the surface of primary particles and/or small aggregate surfaces.

The concentration of zirconium, as determined by inductively coupled plasma analysis, increased with the duration of vibratory milling, even though in the parts per million range. Media wear appears to correspond with the work carried out by the mill. However, media wear did continue, at lower rates, when most of the primary particles had separated.

It is anticipated that improved homogeneity of the metal oxide additives around the $\mathrm{ZnO}$ crystals as a result of decreased particle size would lead to improved grain growth control and better electrical characteristics. However, the concentration of $\mathrm{ZrO}_{2}$ may need to be optimised.

\section{Acknowledgements}

The authors gratefully acknowledge the financial support of Littelfuse Ireland Ltd. We thank the Centre for Microscopy and Analysis Trinity College Dublin for their help with SEM, Ms Mary Bannon, Enterprise Ireland, for help with ICP, Mr Paul Lyons, Enterprise Ireland, for help with porosimetry, and Mr Brendan Daly and Mr Kevin Travers, Littelfuse Ireland Ltd., for help with sample preparation.

\section{References}

[1] D.R. Clarke, Varistor ceramics, J. Am. Ceram. Soc., Vol. 82 (1999) 485-502.

[2] T.K. Gupta, Applications of zinc oxide varistors, J. Am. Ceram. Soc., Vol. 73 (1990) 18171840.

[3] L.M. Levinson and H.R. Philipp, Zinc oxide varistor - A Review, Am. Ceram. Soc. Bull., Vol. 65 (1986) 639-646.

[4] M. Matsuoka, Non-Ohmic properties of zinc oxide ceramics, Jpn. J. Appl. Phys., Vol. 10 (1971) 736-746.

[5] M. Elfwing, R. Osterlund and E. Olsson, Differences in wetting characteristics of $\mathrm{Bi}_{2} \mathrm{O}_{3}$ polymorphs in ZnO varistor materials, J. Am. Ceram. Soc., Vol. 83 (2000) 2311-2314.

[6] L.M. Levinson, H.R. Phillip and G.D. Mahan, Evidence for parallel conduction paths in $\mathrm{ZnO}$ varistors, in Ceramic transactions: advances in varistor technology, L.M. Levinson (ed.) Vol. 3 (1988)145-154.

[7] H. Wang, W. Schulze and J. Cordaro, Averaging effect on current-voltage characteristics of ZnO varistors, Jpn. J. Appl. Phy., Vol. 34 (1995) 2352-2358.

[8] P. Duran, F. Capel, J. Tartaj and C. Moure, Sintering behavior and electrical properties of nanosized doped-ZnO powders produced by metallorganic polymeric processing, J. Am. Ceram. Soc., Vol. 84 (2001) 1661-1668.

[9] A. Sinha and B.P Sharma, Mater. Res. Bull., Novel route for preparation of high voltage varistor powder, Vol. 32 (1997) 1571-1579.

[10] A.R. West, Solid State Chemistry and Its Applications, John Wiley \& Sons, London, (1984) p174 
[11] S. Bernik, N. Daneu and A. Recnik, Inversion Boundary Induced Grain Growth in $\mathrm{TiO}_{2}$ or $\mathrm{Sb}_{2} \mathrm{O}_{3}$ doped $\mathrm{ZnO}$-based Varistor Ceramics, J. Eur.Ceram. Soc., Vol. 24 (2004) 37033708.

[12] R. Puyane, I. Guy and R. Metz, High performance varistor discs obtained from chemically synthesized doped zinc oxide powder, J. Sol-Gel Sci. and Tech., Vol. 13 (1998) 575-578.

[13] S.C. Pallai, J.M. Kelly, D.E. McCormack, P. O'Brien, and R. Ramesh, The effect of processing condition on varistors prepared from nanocrystalline $\mathrm{ZnO}$, J. Mater. Chem., Vol. 13 (2003) 2586-2590.

[14] S. Ananthakumar, H. Varma, P. Perumal, R.P. Prabhakar, A.D. Damodaran and K.G.K. Warrier, Effect of addition of calcined grains on the microstructure and non-linearity features of $\mathrm{ZnO}$ varistors, J. Mater. Sci. Lett., Vol. 13 (1994) 731-733.

[15] K. Eda, M. Inada, and M. Matsuoka, Grain growth control in $\mathrm{ZnO}$ varistors using seed grains, J. Appl. Phys., Vol. 54 (1983) 1095-1099.

[16] J. Glatz-Reichenbach, B. Meyer, R. Strumpler, P. Kluge-Weiss and F. Greuter, New lowvoltage varistor composites, J. Mater. Sci., Vol. 31 (1996) 5941-5944.

[17] L.J. Zhou and H. Yang, Relationship between threshold voltage and the amount of seed grains added for the manufacture of $\mathrm{ZnO}$ varistors, Mater. Lett., Vol. 22 (1995) 187-191.

[18] Z. Brankovic, G. Brankovic, S. Bernik and M. Zunic, ZnO varistors with reduced amount of additives prepared by direct mixing of constituent phases, J. Eur. Ceram. Soc., Vol. 27 (2007) 1101-1104.

[19] D. M Ardle, R. Puyane and M.S. Hashmi, Effect of comminution process parameters on the electrical energy absorption capability of $\mathrm{ZnO}$ varistors, in Hashmi M.S.J., (ed.), Proc. AMPT, Dublin, Vol. 1 (1995) 557-563.

[20] J.A. Rodriguez, J.M. Gallardo and E.J. Herrera, Structure and properties of attrition-milled alumina powder, J. Mater. Sci., Vol. 32 (1997) 3535-3539.

[21] Y.K. Jeong, A. Nakahira, P.E.D. Morgan and K. Niihara, Effect of milling conditions on the strength of alumina-silicon carbide nanocomposites, J. Am. Ceram. Soc., Vol. 80 (1997) 1307-1309.

[22] W.A. Yarbrough and R. Roy, Extraordinary effects of mortar-and-pestle grinding on microstructure of sintered alumina gel, Nature, Vol. 322 (1986) 347-349.

[23] W.D. Kingery, H.K. Bowen and D.R. Uhlmann, Introduction to ceramics, John Wiley \& Sons (1975) p204.

[24] M.C. Kelleher, M.S.J. Hashmi and N. McLoughlin, Control of $\mathrm{ZnO}$ varistor powder properties by attrition milling, Sulaiman (ed.) Proc. AMPT, Malaysia, Vol. 2 (1998) 11861194.

[25] K. Tsutomu, Production of voltage nonlinear resistor, JP5254916A2 (1993)

[26] K. Masaaki, Manufacture of zinc oxide varistor, JP1233704A2 (1988)

[27] C.L. Fan and M.N. Rahaman, Factors controlling the sintering of ceramic particulate composites: 1, conventional processing, J. Am. Ceram. Soc., Vol. 75 (1992) 2056-2065.

[28] C.H. Kim and J.H. Kim, Microstructure and electrical properties of $\mathrm{ZnO}-\mathrm{ZrO}_{2}-\mathrm{Bi}_{2} \mathrm{O}_{3}-\mathrm{M}_{3} \mathrm{O}_{4}$ (M = Co, Mn) varistors, J. Eur. Ceram. Soc., Vol. 24 (2004) 2537-2546. 